\title{
Entre tíos, abuelas y taitas: relatos de los adultos que acompañan a las niñas y a los niños*
}

\author{
Between uncle, grandparents and taitas: Stories of adults \\ accompanying girls and childrren
}

Leydi Yurani Ochoa Duarte

Para citar este artículo: Ochoa, L. Y. (2020). Entre tíos, abuelas y taitas: relatos de los adultos que acompañan a las niñas y a los niños. Infancias Imágenes, 19(1). 121-132.

\section{Resumen}

Este artículo presenta la investigación "Entre tíos, abuelas y taitas. Tres relatos autobiográficos sobre experiencias de viaje en comunidades de Colombia", el cual reconstruyó las experiencias de la investigadora en el hacer comunitario con las familias habitantes de territorios rurales de Putumayo, Cundinamarca y Bolívar. Se integran los conceptos: comunidad, experiencia y cultura. Su enfoque metodológico es cualitativo narrativo, descriptivo y analítico, así como abierto y flexible, sitúa a los sujetos, sus realidades, la vida y la academia en el relato autobiográfico, los cuales expresan las relaciones y las situaciones que propician los adultos para acompañar a los niños y las niñas a ser parte de una comunidad. Los relatos favorecieron el devenir de la memoria de las comunidades y se convirtieron en acervos literarios.

Palabras clave: comunidad, cultura, experiencia, infancia, relato autobiográfico.

\footnotetext{
* Artículo resultado de la investigación "Entre tíos, abuelas y taitas. Tres relatos autobiográficos sobre experiencias de viaje en comunidades de Colombia" desarrollada en la Maestría Infancia y Cultura. Los viajes se realizaron por la autora durante el periodo comprendido entre 2006 y 2017 a comunidades rurales del país. Esto, en el marco de proyectos dirigidos a propiciar espacios para el encuentro con la oralidad, la lectura y la escritura a partir de la relación de las comunidades con los territorios. El documento se consolidó entre agosto del 2017 a julio del 2019 con la tutoría de Piedad Ramírez.

1 Magister en Infancia y Cultura. Licenciada en Educación Artística de la Universidad Distrital Francisco José de Caldas. Docente de la Licenciatura en educación inicial de la Fundación Universitaria Cafam y cocreadora de diferentes programas de la Sala de Lectura Itinerante Tío Mane. Correo electrónico: leydiochoa@yahoo.com.
} 


\section{Introducción}

La investigación incorporó como estrategia metodológica el relato autobiográfico para reconstruir las experiencias acontecidas en el hacer comunitario con tres familias habitantes de territorios rurales de Putumayo, Cundinamarca y Bolívar. Familias con las cuales la autora compartió la cotidianidad, las historias, las celebraciones rituales y artísticas, así como la relación viva, generosa y fundamental que en la infancia establecen con la tierra. De tal manera surge el interés por expresar las realidades, relaciones y situaciones que propician los adultos para acompañar a los niños y las niñas a ser parte de la comunidad que los recibe desde que nacen.

$\mathrm{Al}$ indagar sobre las investigaciones que se han realizado en relación con este tema se encuentran cuatro tendencias que se agrupan en colecciones multilingües con enfoque diferencial desarrolladas de manera concreta en la Estrategia Fiesta de la Lectura ICBF; estas fueron realizadas por antropólogos, escritores e ilustradores quienes recopilaron arrullos, cuentos, juegos, canciones, rondas e historias de comunidades campesinas, indígenas, room y afrodescendientes que habitan el país; y prácticas de crianza empleadas en diferentes culturas y en la recuperación de los saberes ancestrales. Con estas tendencias, si bien aportan al campo de estudio de la infancia, esta investigación se ocupó de ubicar la experiencia de la autora como acontecimiento que permitió establecer las relaciones con los sujetos de las comunidades.

Dado lo anterior, la investigación se inscribió especialmente en dos tendencias que definieron el rumbo metodológico. En las cuales se encuentran, por un lado, la metodología que propone el seminario-taller Biografía y autobiografía de la Maestría en Infancia y Cultura, en el que se estudia el relato autobiográfico como una experiencia que aporta a la construcción de identidad, que nutre el pensamiento pedagógico a partir de los sujetos y sus realidades; se trata de un método de reconocimiento y análisis de las ciencias sociales cuyo propósito es construir un camino de autoconocimiento que lleva a otorgar nuevos significados de las vivencias (Santamaría, 2010). Por otro lado, la tendencia de las investigaciones del grupo Diverser de la Universidad de Antioquia, quienes proponen otras metodologías para la producción de conocimiento en perspectiva de la diversidad cultural (Rojas, 2014) e investigar desde las raíces y los significados de vida (Green, 2011), entre otros.

Se estudian conceptualmente los principios que Larrosa (2006) propone sobre la experiencia; al ser esta en sí misma sinónimo de recorrido, viaje, travesía o aventura, la cual sucede porque el sujeto está dispuesto a dejar que algo le pase por la aparición de algo o alguien. Se une con el concepto de comunidad, que en esta investigación se ubica como categoría analítica, el cual forma parte del pensamiento crítico y alternativo latinoamericano; con un horizonte de sentido que permite comprender los procesos emergentes, aquellos que revindican otras maneras de ser, estar y actuar juntos, materializados en los distintos proyectos de buen vivir que posicionan la idea de "un mundo donde quepan muchos mundos" (Escobar, 2018, p. 29). Esta se apoya, además, en la construcción de otros mundos posibles gestados en el ser con otros y de un "nosotros", conciencia colectiva que se convierte en un desafío político y ético en la toma de decisiones por, con y para las comunidades en coherencia con las realidades, las proyecciones y las transformaciones propias (Torres, 2013). Y la cultura desde el enfoque semiótico e interpretativo, situada en el entendimiento y en el corazón de los humanos (Geertz, 2003).

Para la escritura de los tres relatos se construyó un hilo narrativo, el cual se apoyó de fuentes como bitácoras de viaje, imágenes, escritos y archivos de audios de conversaciones espontáneas registradas en años anteriores. Se integraron voces de los sujetos de las comunidades quienes, también, expresaron sus apreciaciones, precisaron algunos datos y aportaron elementos narrativos que consideraban pertinentes tener en cuenta. Ellos y ellas reconocieron la importancia de los relatos ya que documentan la vida de las familias y comunidades, desde la experiencia de un sujeto que poco a poco fue siendo parte. Los relatos se convierten en acervos orales y escritos, soportes para transmitir y mantener la memoria, reflejar la vida de los pueblos, los cuales expresan realidades, relaciones y situaciones que propician los adultos para acompañar a los niños y las niñas que son y serán parte de una comunidad. 


\section{La experiencia del viaje de la investigadora como elemento de estudio}

La investigación ubicó a la autora como sujeto que se estudia a través de la experiencia del viaje y las relaciones fundadas con las tres familias. En ese sentido, los relatos autobiográficos en sí mismos expresan las situaciones que se enmarcan dentro de la experiencia que según Larrosa es "eso que me pasa [...] el modo de habitar el mundo de un ser que existe, de un ser que no tiene otro ser, otra esencia, que su propia existencia: corporal, finita, encarnada, en el tiempo y en el espacio, con otros" (2004, p. 5) y ubica los principios: exterioridad, alteridad y alineación, los cuales suponen un acontecimiento externo que no depende del sujeto y aclara que no hay experiencia sin la aparición de alguien; esta no se reduce al acontecimiento sino que desobedece a la voluntad. Los principios de subjetividad, reflexividad y transformación son un movimiento de ida y vuelta; de ida porque va al encuentro con eso que pasa y de vuelta porque lo externo afecta directamente al sujeto. Su carácter singular "al pasar por mi o en mí, deja una huella, una marca, un rastro, una herida [...] una superficie de sensibilidad en la que algo pasa" (Larrosa, 2006, p. 91) es dejar que algo le pase, estar receptivo, abierto, sensible, vulnerable, expuesto y dispuesto a transformarse o a formarse. El principio de pasaje y pasión es un recorrido, un viaje, una travesía o aventura la experiencia supone entonces una salida de si hacia otra cosa, algo que viene; por tanto, está impregnada de incertidumbre.

El principio de finitud, cuerpo, vida explica que la experiencia "no tiene otra esencia que su propia existencia finita, corporal, de carne y hueso" (Larrosa, 2006, p. 110). Así pues, la experiencia fue la base para establecer las relaciones. Primero con las personas integrantes de las familias y de las comunidades, con quienes fue posible encontrasen dentro de las acciones que se desarrollaban en el marco académico. En concreto, durante el I Congreso Internacional de Pedagogía, Currículo e Historia de la Educación Pensar la educación de América Latina organizado por la Universidad de Nariño; siendo este parte de los requisitos para cursar la electiva Pensamiento de Simón Rodríguez y el seminario Artes escénicas y literatura de la Licenciatura en Educación Artística de la Universidad Distrital Francisco José de Caldas. Si bien estas acciones permitieron el encuentro con las personas de las comunidades, los vínculos trascendieron de lo académico al hacer comunitario mediante el desarrollo de propuestas en relación con la lectura, la oralidad y la escritura a partir de la relación que las comunidades tienen con sus territorios. Gracias a las relaciones fundadas con ellos y ellas se dio la posibilidad de conocer a sus familias y a sus comunidades. La unión con Sandra y Aurita Tisoy estableció conexión con la familia Tisoy Tandioy del departamento del Putumayo, municipio de Santiago-Manoi, Vereda Vichoy; la unión con Horacio Castro permitió conectar con la familia Obando Obando del departamento de Cundinamarca, municipio de Junín, Vereda San Francisco; y con Henry Villalba la conexión con la familia Villalba Meléndez del departamento de Bolívar, municipio San Juan de Nepomuceno, corregimiento de San José del Peñón. Sur, centro y norte de Colombia respectivamente.

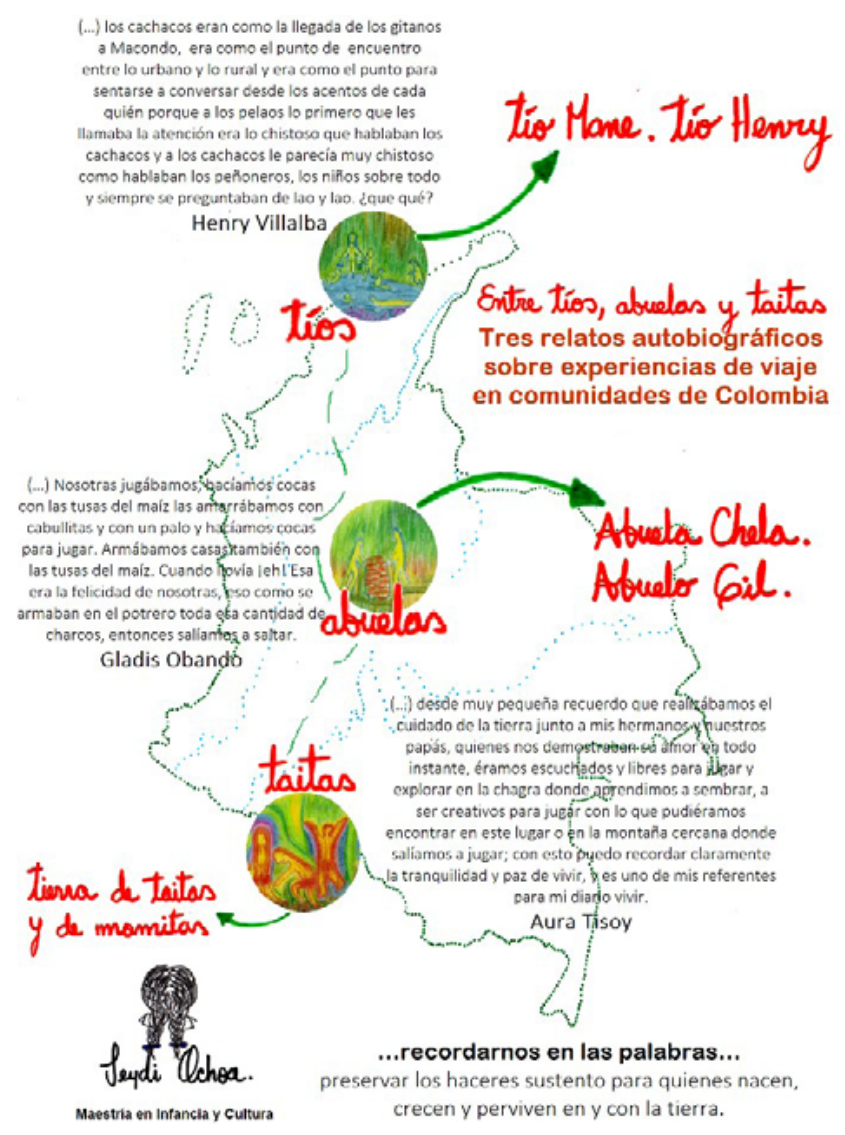

Figura 1. Mapa de ubicación geográfica de las comunidades.

Fuente: elaboración propia de la autora. 


\section{Metodología}

La investigación se ubicó a nivel metodológico dentro del enfoque cualitativo. Su carácter fue narrativo, descriptivo y analítico, así como abierto y flexible, lo cual permitió construir un método a partir de la experiencia del viaje. Es decir, no se hizo trabajo de campo situado, ya que no se estudian los sujetos de las comunidades, sino que se estudió la experiencia del viaje de la investigadora y las relaciones fundadas con las tres familias.

Se integraron los aprendizajes de la maestría, los cuales a través de sus seminarios académicos permitieron direccionar la formulación del proyecto de investigación, así como el desarrollo y la consolidación de la metodología. Los seminarios directamente integrados fueron: Historias e historias de infancias en América Latina y Colombia, Historia de vida, biografía y autobiografía y Lengua materna, narrativas, lenguajes y poética en niños y niñas: desarrollos infantiles por el habla y las escrituras. Estos aportaron estudios sobre cómo los relatos son métodos para el análisis, interpretación y lectura de realidades empleados en las ciencias sociales y humanas con autores como Jerome Bruner (1997) y Flor Alba Santamaría (2010).

Sobre el relato y el relato autobiográfico.

Estrategia metodológica

El relato autobiográfico fue la estrategia metodológica puesta en funcionamiento para reconstruir la experiencia de viaje, ya que ofrece la posibilidad de narrar lo vivido, recuperarlo y convertirlo en conocimiento. Al incorporarlo fue necesario recordar las experiencias y traerlas al presente a través de la palabra.

Bruner (1997) plantea nueve universales sobre las realidades narrativas que están presentes. En ellas se encuentra contrastes, confrontaciones, entre las cuales están: los relatos suceden en un tiempo determinado y Ilevan significados asignados por los acontecimientos que ocurren dentro de unos límites; tienen una razón de ser, es decir, se escriben con intención; tienen la posibilidad de ser interpretados de diferentes maneras; deben ir en contra de las expectativas del autor y del lector; los hechos son en función del relato, el cual consigue su referencia en sí mismo y lo problémico refleja el desajuste o conflicto de quien relata; negocian con la cultura; al reconstruir el pasado lo convertimos en historia y construimos relatos para conservar la identidad.

Por su parte, Santamaría (2010) presenta el relato autobiográfico como una experiencia que aporta a la construcción de identidad. Es un método de reconocimiento y análisis de las ciencias sociales con el propósito de construir un camino de autoconocimiento que lleva a otorgar nuevos significados de las vivencias direccionadas al pensamiento pedagógico en unión con los planteamientos teóricos de la lingüística del acontecimiento y la sociolingüística. Santamaría considera que relatar no es solo describir una serie de hechos o eventos, sino que:

[...] para que haya relato, también se requiere de un narrador o locutor provisto de intencionalidad, es decir, del deseo de transmitir algo a alguien, esto es, de contar a un destinatario o interlocutor. Además, para que una secuencia de eventos contados se convierta en relato es necesario un contexto.

Relatar es una búsqueda constante e infinita; responde a las preguntas fundamentales que se plantea el hombre: ¿Quiénes somos? ¿Cuál es nuestro origen? ¿Cuál es nuestro destino? ¿Cuál es la verdad de nuestro ser? El hombre no cesa de construir a través de su imaginario relatos de los hechos y los gestos de los seres humanos que revelan parcelas de esa verdad.

Entonces, relatar es una actividad lingüística que se desarrolla en medio de cierto número de tensiones y hasta de contradicciones, como las existentes entre relatar la realidad y la ficción, la unidad y la pluralidad, entre otras.

En conclusión, el relato es una totalidad, y lo narrativo, uno de sus componentes.

(Santamaría, 2010, p. 54)

Sobre la ruta metodológica

El grupo de investigación Diverser, de la Universidad de Antioquia, creó la pedagogía de la madre Tierra y propone otras metodologías para la producción de conocimiento desde una perspectiva de la diversidad cultural (Rojas, 2014). La autora interpela los mecanismos de validación del conocimiento, 
sugiere métodos participativos con los sujetos de las comunidades e invita metodológicamente a:

[...] crear nuevas combinaciones y formas sólo es posible a partir de procesos también creativos en un sentido amplio, creación no como punto final del camino sino como un alcance del camino, donde es posible sentir y decir con el corazón. (Rojas, 2014, p. 69)

Otras investigaciones por esta línea son la metodología propuesta en la tesis doctoral Investigar desde las raíces y los significados de vida que refiere al origen profundo que da cuenta de la cosmogonía de la cultura de un pueblo (Green, 2011), en la cual la recuperación de la historia oral y su interpretación, de acuerdo con el contexto histórico actual, nos exige profundizar las palabras de la lengua. Nataly Domicó (2018) creó junto con su comunidad Embera eyabida del cabildo mayor indígena de chigorodó el método de investigación el vuelo del colibrí, basado en la historia de origen del agua (Domicó, 2018). Asimismo, Arenas (2017) integró los principios de la pedagogía de la madre Tierra y construyó una metodología comunitaria que afirma como modo de vida que le ha permitido reafirmarse desde la colectividad e invitó a

[...] seguir investigando y tejiendo lo común en la comunidad, porque este representa un recurso inacabado, así el conocimiento es puente en espiral que constantemente se transforma, porque son humanos las que las crean y hacen, es por ello, que se deja temas para futuros análisis. (Mateo, 2017, p. 146)

\section{Metáfora de tejido: Vida y academia}

Los anteriores referentes inspiraron la ruta metodología de la investigación, pues en diálogo con principios de la pedagogía de la madre Tierra se ubica al sujeto erguido (Zemelman, 2002), quien decididamente se compromete y se siente responsable de su historia y del devenir de su pueblo (Rojas, 2014, p. 48); el pensamiento en tejido que manifiesta la diversidad de los procesos, los sujetos y abre la pregunta sobre el lugar y la comprensión del sujeto mestizo, entendiendo que la Tierra es la madre de todos y todas quienes la habitamos (Green, 2011). La investigadora toma estos principios y ubica su historia de origen mestizo, establece una la ruta metodológica a la que llama las trenzas de la abuela Cleofe (en honor al peinado de dos trenzas representativo de las campesinas). Metáfora de tejido que reúne, por un lado las vivencias o experiencias a través de lugares, personas, situaciones y, por otro, la academia con los conceptos: comunidad, infancia, cultura, experiencia y relato autobiográfico. Tejidos entre sí y sujetados con el hecho investigativo y las proyecciones que resultan del mismo.

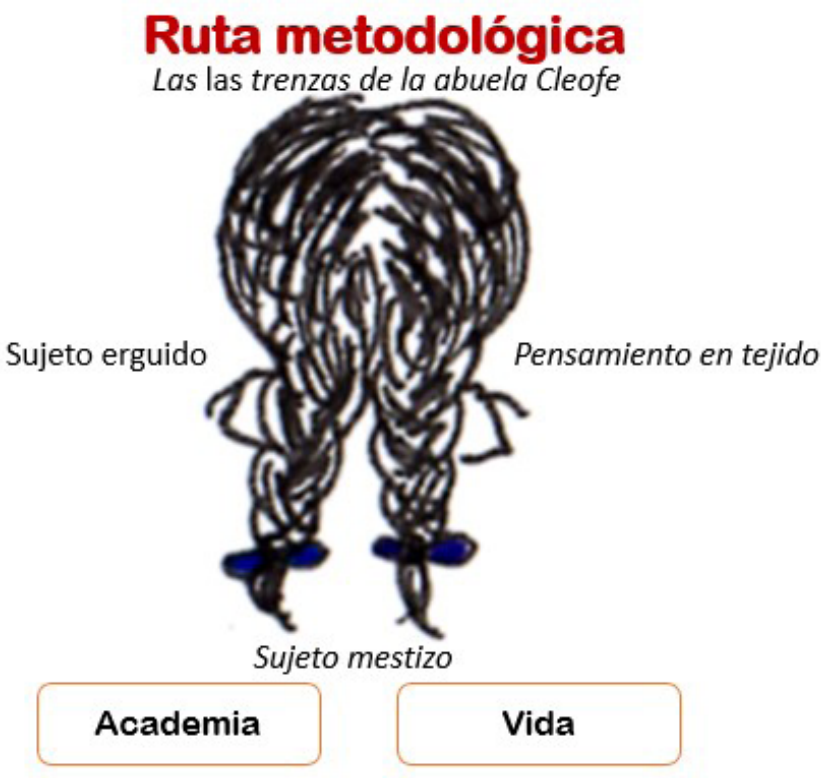

Figura 2. Ruta metodológica.

Fuente: elaboración propia de la autora.

\section{Los relatos autobiográficos}

Relatar acontecimientos ocurridos requiere un ejercicio de memoria. Platón afirma que la memoria es la "representación de una cosa ausente" (1925, p. 8); representaciones manifestadas en las imágenes guardadas de las situaciones que nos impresionan y que trascienden en el tiempo. Aristóteles decía que "la memoria es del tiempo" (1962, p. 28). Mem Fox (1988), en el libro álbum: Guillermo Jorge Manuel José, define la memoria como algo que se recuerda, algo tibio, algo muy antiguo, algo que te hace llorar, algo que te hace reír, algo precioso como el oro. 
La memoria tiene una estrecha relación con el pasado, con aquello que ya sucedió, que guardamos y que cuando nos ponemos en la tarea de recordar aparecen aquellos momentos como hilos invisibles que están con nosotros. La memoria dice Ricoeur (2000) es la relación que tenemos con nuestro pasado y, por tanto, es aquello que nos constituye para ser quienes somos en el aquí y en el ahora.

Así fue como se escribieron los tres relatos autobiográficos, uno por cada familia: Tío Mane. Tío Henry, zona norte familia Villalba Meléndez; Abuela Chela. Abuelo Gil, zona centro familia Obando Obando; Tierra de taitas y mamitas, zona sur familia Tisoy Tandioy. A continuación, se presentan algunos fragmentos de los relatos que expresan las situaciones en las que están presentes las relaciones entre los adultos, los niños y las niñas de las comunidades:

Las carreras de morrocoyos era otro momento de la programación del festival que implicaba preparación durante todo el año. Morrocoyo es el nombre que le daban a las tortugas; por lo general cada niño con su papá se dedicaba a buscar las maneras de entrenar a la tortuga escogida para participar. Algunas mamás les tejían accesorios para ponerlos en el caparazón y así identificarlas en el momento de la carrera. Sucedía que en el momento de la competencia algunos morrocoyos no salían de su caparazón y se quedaban en el punto de salida, otras se desviaban del camino y otras se quedaban quietas a medio camino. Uno de los morrocoyos ganadores fue el de Jorge Andrés, el nieto de la señora Nelly y el señor Benigno. Aquel título de ganador enorgullecía, como también el solo hecho de participar, les daba un lugar dentro del festival.

Henry aquel ser que siente afecto por su tierra, que sus ancestros le auguraron sembrándole el ombligo en el árbol del patio de la casa, para que no se fuera del pueblo o retornara en caso de irse, como él mismo lo decía. En ese momento, tenía el propósito de emprender la recuperación de la sala de lectura Tío Mane, reconociendo que al llamarla de esa manera hacia un importante homenaje al tío Manuel Meléndez, a quien todos en el pueblo le llamaban Tío Mane, lo recordaban como un elegante montador de burro a quien le llamaba Capsulo, un tío contador de historias como Henry, conocedor de la medicina natural de la región como don Isma el papá de Henry, cultivador de yuca, ñame, tabaco, auyama y maíz, como muchos de los hombres del pueblo donde nació Henry. El Tío Mane representaba la oralidad, los saberes y la relación con la tierra. Al recuperar la sala de lectura también se continuaba recuperando la riqueza y la permanencia de la oralidad como legado de los mayores. (Tío Mane. Tío Henry)

La cocina es el lugar de encuentro, el lugar donde emerge la conversación, donde la escucha se agudiza, donde los silencios son pausas que hablan lo que no puede decir la palabra, allí durante el tiempo que se preparan los alimentos, durante el momento en que se comen los alimentos se pasa gran parte del tiempo, y entre el acto de cocinar y comer se va recordando la infancia de los nietos, de los hijos y de los mismos abuelos. La abuela recordaba cuando a Horacio de un poco más de un año, lo bañaba en un platón de aluminio con agua que el sol calentaba de manera natural, decía que allí Horacio se quedaba hasta que los dedos de las manos y de los pies le quedaban arrugados. En la cocina, al calor del fogón, con el olor a leña, pelando papas, desgranando fríjol o esperando que estuviera listo el alimento, contaban las historias que recordaban y compartían a quienes llegaban por primera vez de visita. (Abuela Chela. Abuelo Gil)

Iban llegando de las escuelitas de las veredas los estudiantes de la escuela bilingüe lachai Wasi Carlos Tamabioy que quedaba en el mismo cabildo. La programación de ese día estaba dirigida a los niños y las niñas de la comunidad; hicieron el desfile desde el cabildo a la plaza central del pueblo, allí seguimos danzando, tocando y cantando.

La programación continuaba con los juegos tradicionales: carreras de bandereros, los niños corrían con banderas de colores alrededor de la plaza del pueblo; juegos del chilacuan, los niños tiraban los chilacuanes (frutos verdes similar a papayuela) por el aire, conocidos como la fruta del tómbolo, durante el juego se podía ver la lluvia de chilacuanes que iban de un lugar a otro hasta que se integraban con la tierra; ortiga (planta que tiene pequeños pelos urticantes que dejan la piel roja e inflamada), con anterioridad era recolectada de la chagra y puesta en canastos que tejen las mayoras-abuelas artesanas y sabedoras de la comunidad, los niños cargaban canastos llenos de ramas de ortiga en la espalda, así caminaban en 
el desfile hasta que llegaba el momento de bajar los canastos de la espalda y dejar las ramas a disposición de quienes querían ortigarse, ortigar o ser ortigados, en medio de este juego se escondían, corrían, reían y algunos prevenidos se tapaban muy bien el cuerpo, sin embargo, por más bien que se taparan, la cara y las manos no se salvan de ser ortigadas; muñecos de maíz, eran muñecos que elaboraban artesanalmente con hojas secas de maíz, también los cargaban durante el desfile y cuando llegaba el momento los lanzaban al aire como los chilacuanes, de un lugar a otro convirtiéndose ahora en lluvia de muñecos de maíz que se iban desarmando hasta retornar a la tierra como hojas secas. (Tierra de taitas y mamitas)

\section{Los aprendizajes}

\section{Relatos y comunidad}

Una vez escritos los relatos se compartieron con los representantes de cada comunidad. Ellos y ellas expresaron sus apreciaciones, precisaron algunos datos y aportaron elementos narrativos que consideraban pertinentes tener en cuenta para las versiones finales. Al integrar a las personas de las comunidades las reflexiones y los aprendizajes se construyeron colectivamente. Ahora bien, en sí mismos los relatos expresan situaciones cotidianas que reflejan la compañía y el cuidado, no solo entre padres e hijos, sino entre tíos, abuelos, primos, amigos y vecinos; adultos que forman parte de una comunidad que propicia la participan espontánea de los niños y las niñas.

Los contenidos de los relatos están construidos a partir de la siguiente estructura: 1) los sujetos y sus territorios, 2) las celebraciones rituales, artísticas o cotidianas, los saberes propios, las situaciones de la vida diaria compartidas y 3 ) los haceres comunitarios. Y, dentro de las descripciones, emergen elementos que definen a una comunidad, tales como: los distintos proyectos del buen vivir; la creación de vínculos; la construcción del nosotros y del ser con otros; los sentimientos y significados compartidos; la pluralidad de los sujetos, lo común en lo diferente; la interdependencia con los demás que crea conciencia subjetiva de pertenecer a una estructura más amplia, estable y fiable, las maneras de ser, estar y actuar juntos en familia y comunidad que da al sujeto; "además de cobijo y sustento, normas, modos de pensar, de sentir, percibir, expresar, experimentar, saber, soñar, creer, sufrir y morirse" (Torres, 2013, p. 205).

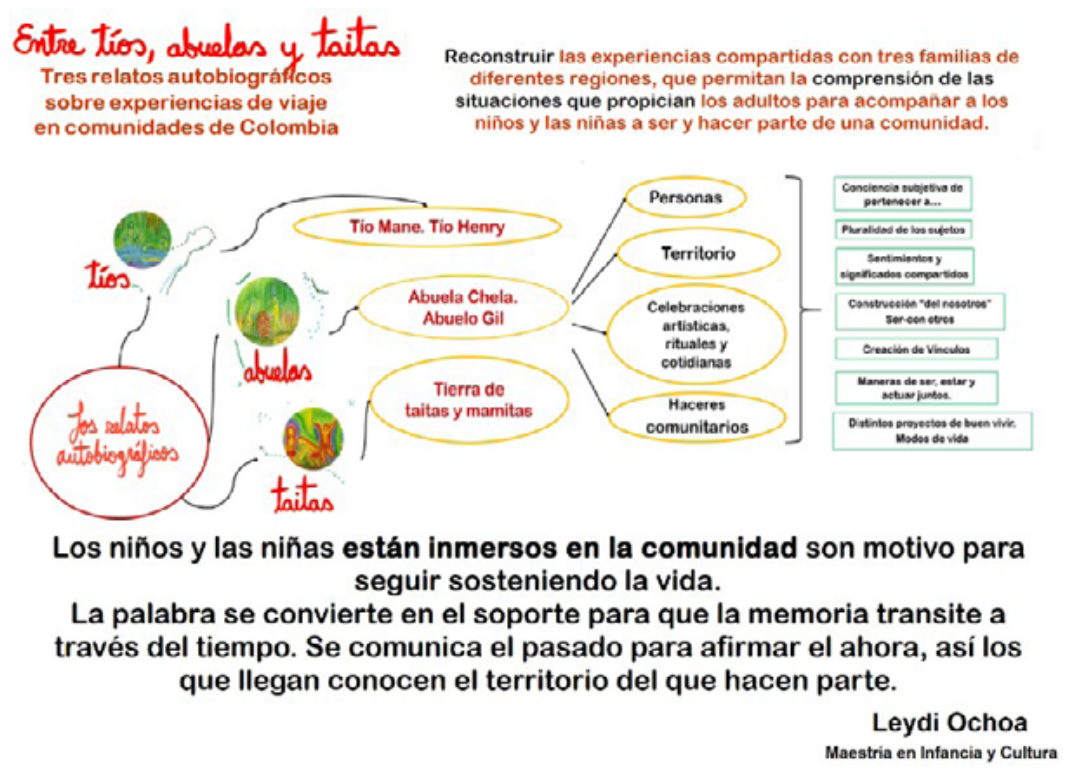

Figura 3. Relatos, estructura y categorías.

Fuente: elaboración propia de la autora. 
Los sujetos y sus territorios

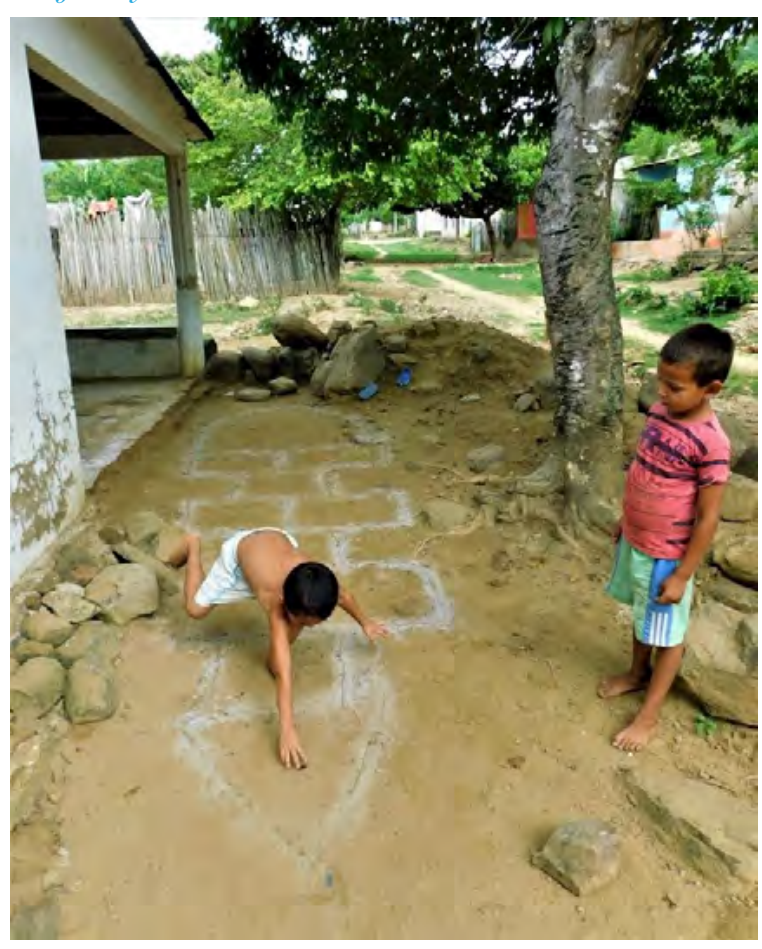

Figura 4. San José del Peñón. Avión en tierra.

Fuente: Henry Villalba.

Cada relato inicia con la descripción de la manera en la que se establecieron relaciones con las personas que abrieron la posibilidad de conocer a las familias y a las comunidades. Es decir, relata cómo fue la unión con Sandra y Aurita Tisoy, de la familia Tisoy Tandioy, con Horacio Castro de la familia Obando Obando y con Henry Villalba de la familia Villalba Menéndez. Dentro de las características que los une se encuentra que ellos y ellas salieron de sus comunidades a realizar los estudios superiores, motivo por el cual se establecieron las relaciones; otra característica es el arraigo por su territorio y que llevan en alto sus raíces, aspecto que fundamenta la relación inmanente con el territorio ${ }^{2}$ concibiéndolo como "entes vivos con memoria, un espacio vivencial de lo sagrado y lo cotidiano, con un derecho propio que encarna la relación con otros seres y el manejo o relaciones que se tienen con ellos" (Escobar, 2018, p. 30). Concepción inspirada en la cosmovisión de comunidades que se

2 Aspecto transversal y fundamental en todos los relatos. constituyen a partir de la vida con y en la tierra. El territorio es el lugar que acoge al nativo y al visitante, en el que se cuidan a todos los seres vivos; el lugar donde se siembran los alimentos, donde se construye las casas, donde se comparte vida. La tierra más allá de ser un recurso es la vida misma, el lugar que nos acoge para nacer, crecer, permanecer y fluir. Allí se materializa la interrelación ${ }^{3}$ con todo lo que existe. Por ejemplo, en el relato Tierra de Taitas y Mamitas la chagra es un lugar de encuentro permanente en el que se concibe el buen vivir. Desde los principios de la vida Inga el Suma Kaugsai wasikamakuna o kawagkuna alpita son cuidadores de la tierra; Aurita Tisoy nos comparte lo que es la Chagra, el Suma Kaugsai y como los adultos la acompañaron a ser parte de su comunidad:

He tenido la oportunidad de nacer en el vientre de una familia Inga ${ }^{4}$ en la vereda Vichoy de Santiago, Putumayo (Colombia). Comienzo por reconocer con gran amor el lugar en el que crecí ya que ha sido fundamental para mi poder aprender, vivir y compartir con mi familia, ya que desde muy pequeña recuerdo que realizábamos el cuidado de la tierra junto a mis hermanos y nuestros papás, quienes nos demostraban su amor en todo instante, éramos escuchados y libres para jugar y explorar en la chagra ${ }^{5}$ donde aprendimos a sembrar, a ser creativos para jugar con lo que pudiéramos encontrar en este lugar o en la montaña cercana donde salíamos a jugar; con esto puedo recordar claramente la tranquilidad y paz de vivir, y es uno de mis referentes para mi diario vivir. (Aura Esperanza Tisoy Tandioy)

\section{Las celebraciones rituales, artísticas y cotidianas}

La descripción de las celebraciones que hacen parte del ser y del hacer de las comunidades: el Festival del Dulce y de la Chicha de San José del Peñón, las Fiestas del Arcoíris, Kalusturrindas Atun Pucha en Vichoy-Manoi y las celebraciones de fin

3 Sobre este concepto Arturo Escobar dice: las culturas matrísticas surgen y prosperan "en un trasfondo de conciencia de interconectividad de toda la existencia, y, por lo tanto, no puede sino vivirse continuamente en el entendimiento implícito de que todas las acciones humanas tienen siempre consecuencias en la totalidad de la existencia" (Maturana y Verden, 1993, p. 47, cit. en Escobar, 2018).

4 Inga: comunidad indígena descendiente del imperio Inca del Perú.

5 Chagra: cultivo tradicional de las comunidades de los Andes, donde se cuidan variedad de plantas para distintos fines. 
de año en la vereda San Francisco en Junín. En las celebraciones de Vichoy y San José del Peñón están presentes elementos propios como música, danza, alimentación, juegos, vestuario tradicional, el cacho como instrumento, la chicha en un lado es dulce y morada y en el otro lado es amarilla y fermentada; las programaciones de las celebraciones integran a niños, niñas, jóvenes, adultos, adultos mayores; se evidencia la unión entre pueblos: en Manoi se integran a las celebraciones del pueblo Camëtsá y en San José participan grupos musicales y de danza de corregimientos cercanos. En ambos lugares se integra a los visitantes: amigos que Ilegan de otros lugares a quienes se les enseñan sus costumbres, por ejemplo, les enseñan la manera de repartir chicha en las kalusturindas, o la manera de preparar el mote de queso en San José del Peñón.

Al participar en las celebraciones propias de cada lugar es posible conocer las maneras ser, estar y actuar. La programación reúne el acontecer de los pueblos, como se describe en cada uno de los relatos. Por ejemplo, la carrera de morrocoy o el lanzamiento de los chilacuanes, acciones propias de los territorios que guardan significados y proyectan la continuidad de la historia. Se evidencia el esfuerzo por mantener la esencia de las celebraciones, lo cual recae en las personas que las mantienen vivas, pero que también cuidan el sentido que estas guardan desde tiempos pasados.

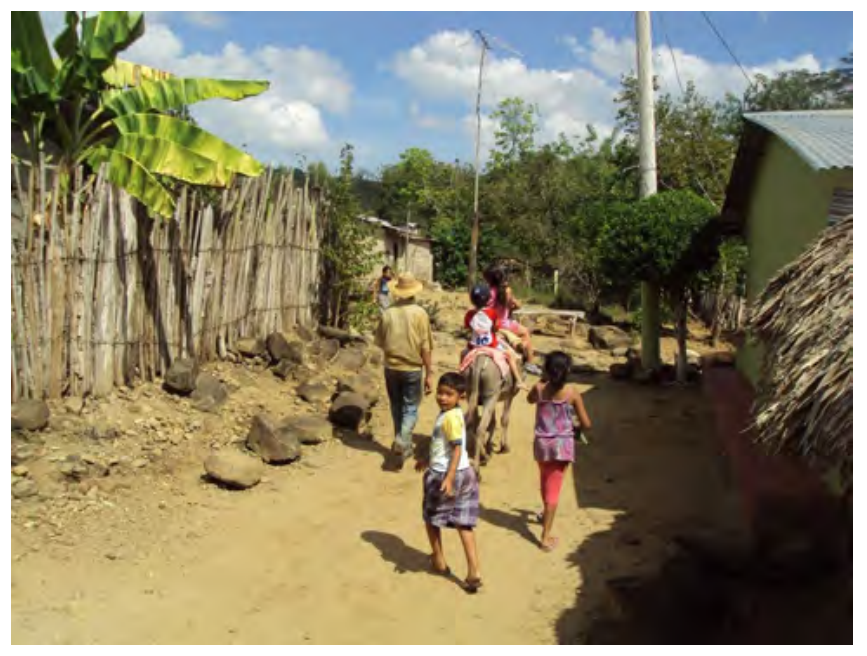

Figura 5. San José del Peñón, don Benigno, sus nietos y el burro.

Fuente: Henry Villalba.
Cada una de las acciones que suceden en las celebraciones reflejan los saberes propios, la particularidad de los alimentos y las situaciones de la vida diaria. Los puntos en común son la presencia del maíz y los alimentos que derivan de él, la leche y el queso, la práctica del tejido con sus diferentes técnicas y la relación de aprecio y respeto por los mayores de la comunidad. En San José del Peñón se manifiesta a través de los homenajes que les hacían a los mayores en el festival y en Vichoy durante el Divichidu visitan a las familias que conforman la comunidad y con el canto "bailemos juntos mientras vivamos, cantemos juntos mientras vivamos" danzan con los mayores para celebrar la vida. En la vereda San Francisco se acompaña a la abuela y al abuelo cada vez que se tenga la posibilidad, asimismo se reúnen a compartir los rituales de las celebraciones de fin año. A lo largo de los relatos se encuentran transversalmente los saberes de los mayores, manifestados en los oficios diarios trasmitidos espontáneamente en la medida en que se comparte la vida. Los acontecimientos giran en torno a los tíos, los abuelos, los taitas y las mamitas que son los mayores de las comunidades; se exaltan sus palabras, sus saberes y haceres diarios.

\section{Los haceres comunitarios}

La memoria se construye y se materializa en y con las acciones cotidianas que comparten niños, jóvenes con sus mayores, en la siembra, en los vestuarios, en las músicas, en las celebraciones y en los rituales, acciones fundamentales para la pervivencia. También se encuentran las propuestas que han sido pensadas y construidas por las personas de las comunidades como la Sala de Lectura Tío Mane; un lugar, que si bien, antepone ser "sala de lectura" fue un pretexto para reconocer y mantener en el recuerdo las acciones de los mayores sabedores: el "Tío Mane" de San José del Peñón y del Taita Gabriel Tisoy en Vichoy, con ellos perdurará el encuentro con la oralidad, los saberes, la relación con la tierra, las corporalidades, las músicas, el juego, entre otros lenguajes expresivos.

Con la propuesta de las salas de lectura la palabra se convierte en el soporte para que la memoria transite a través del tiempo. Permite recordar historias, comunica el pasado para reafirmar el ahora, 


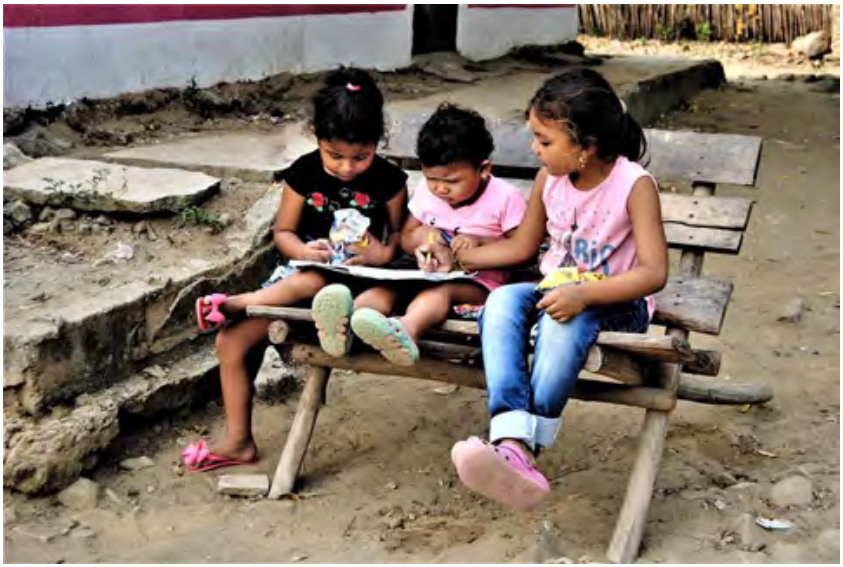

Figura 6. San José del Peñón, niñas leyendo.

Fuente: Henry Villalba.

así los niños, niñas, jóvenes y visitantes van conociendo lo que constituye el lugar al que Ilegan y del que hacen parte. Para Henry el hecho de Ilamar a una sala de lectura con el nombre Tío Mane es 130 engrandecer simbólicamente a los mayores. Dice Henry, refiriéndose al Tío Mane:

Tío Mane era tío de todo el mundo y no era tío de ninguno, se construyen como esas figuras dentro de los pueblos para uno tener anclada la imaginación en algo, se ancla esa imaginación en unas cosas cotidianas, siempre hay que anclarlo y el tío Mane vivió muchas cosas, pero se le crearon también muchas cosas alrededor y que no lo podría decir otra persona sino el tío Mane, y eso es parte de esas metáforas que tienen los pueblos para generar esas supervivencias o esas maneras de hacer "resistencia". (Henry Villalba)

\section{Conclusiones y continuidades}

Las metodologías, particularidades y apuestas para la generación de conocimiento articulan los contenidos de los seminarios abordados en la Maestría Infancia y Cultura y las metodologías desde la diversidad cultural. Por estas razones se construye una ruta del camino investigativo a partir de la metáfora del tejido incorporando el concepto del sujeto erguido y la pregunta por el sujeto mestizo; esta ruta ubica la vida y la academia en diálogo constante con el hecho investigativo. Además, se integran las voces, percepciones y saberes de las personas de cada una de las comunidades; ellos y ellas validaron, retroalimentaron e intervinieron tanto en las versiones finales de los relatos como en la construcción de las reflexiones y los aprendizajes del documento de investigación.

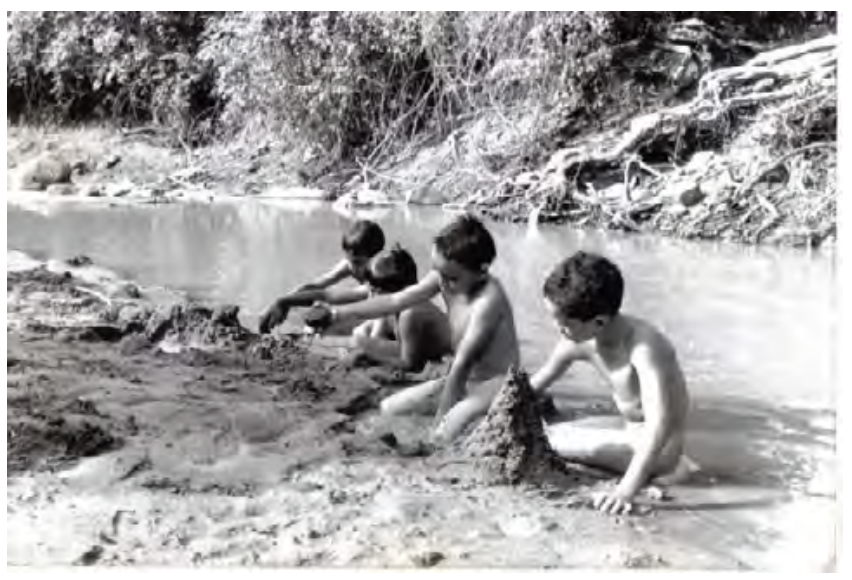

Figura 7. San José del Peñón, niños jugando a la orilla del arroyo.

Fuente: Henry Villalba.

El concepto de comunidad como categoría de análisis para la investigación latinoamericana amplía y dialoga con el campo de la cultura y el enfoque semiótico e interpretativo, las concepciones de infancia desde las realidades y las relaciones entre niños, niñas y adultos de tres familias de Colombia.

Los relatos construidos dan un lugar a "la palabra" y aportan a la pervivencia de los pueblos, se constituyen en acervos orales y escritos los cuales se convierten en soportes que mantienen la memoria viva, transmiten los modos de ser y estar de las familias y las comunidades, recuerdan el hacer y el ser de los territorios, a través de estos acervos orales y escritos que comunican el pasado y reafirman el ahora. Así, niños, niñas, jóvenes y visitantes conocen lo que constituye el lugar al que llegan y del que hacen parte. Graciela Montes habla del espacio poético (2001) lo define como un territorio construido por palabras, un espacio de libertad que ensancha la vida, al que se puede ingresar cuantas veces se quiera y se requiera; ella lo encontró con su abuela, en los libros y en el juego. 
La facultad oral que atraviesa al ser humano en sus orígenes la desarrolla en el seno de su propia cultura. Aun cuando la lengua oral permite a los niños y las niñas nacer psíquicamente y adquirir la estructura sonora de la lengua de la comunidad lingüística que le ve nacer (Cabrejo, 2012). De esta manera, también se organiza el entramado de signos, símbolos y sentidos (Geertz, 2003) que le permitirán acceder a la cultura y fuerza al hombre a dominar el lenguaje como medio de interpretar y regular la cultura (Bruner, 1997). La cultura situada en el concepto semiótico e interpretativo que estudia los sistemas simbólicos de los pueblos desde el entendimiento y en el corazón de los humanos (Geertz, 2003) permiten la comprensión de los sentidos que constituyen la vida del sujeto en la comunidad.

La acogida que brinda una familia da la posibilidad de conocer a la comunidad. Las personas forman parte de una familia, una familia tiene vínculos con una comunidad y una comunidad hace parte de la cultura.

Dentro de las situaciones descritas en los relatos, los niños y las niñas son quienes reciben a los visitantes y los invitan a conocer su territorio; por lo que esperan con regocijo las fechas de las celebraciones. Ellos y ellas son acompañados, cuidados, alimentados, vestidos; son quienes participar en las danzas, en los cantos, en los rituales. Quienes comparten día a día con los hermanos, primos, sobrinos, tíos, abuelos, padres, amigos, vecinos. Los niños y las niñas están inmersos en la comunidad, son motivo inmanente para seguir sosteniendo las situaciones que propician los adultos, son la posibilidad de dar continuidad y permanencia a la vida.

El carácter narrativo de la investigación incorpora la creación literaria y proyecta la divulgación de los relatos a las familias y comunidades en el marco de la Feria del Libro Itinerante Tío Mane ${ }^{6}$, así como lo sugirió Henry Villalba:

6 Para el año 2020 llega a su décima versión. La Feria del Libro Itinerante Tío Mane fue una idea colectiva entre visitantes y habitantes de San José del Peñón, con quienes se pensó una feria donde no se vendieran libros, sino que aportara a la comprensión de la relación que existe entre palabra, cotidianidad, territorio, comunidad y memoria, guiados por la pregunta: ¿cómo se lee, escribe, habla y escucha en la tierra y con la tierra? Se crearon acciones centradas en exaltar las maneras en que las personas de San José del Peñón se relacionan con las palabras en la cotidianidad.
[...] va a ser una oportunidad para que esos relatos no se queden allí, sino que los pelaos puedan consultar en la misma sala de lectura en el mismo espacio con el que hemos estado batallando durante tanto tiempo para que llenen de significado el ahora a partir de cosas que se han vivido necesariamente en San José del Peñón. (Henry Villalba)

\section{Agradecimientos}

A la amistad, a la familia, a las comunidades; a los seres corpóreos e incorpóreos aquí presentes.

\section{Referencias}

Aristóteles (1962). De la memoria y el recuerdo. Traducido por Francisco de Samaranch. Citado en Ricoeur, P. (2000). Memoria, historia y olvido. Fondo de Cultura Económica.

Bruner, J. (1997). La construcción narrativa de la realidad. En la educación puerta de la cultura. Machado Libros.

Cabrejo, E. (2012). Ponencia: Lectura en voz alta y desarrollo infantil temprano. Bogotá: Memorias Encuentro internacional de formación de lectores en la primera infancia.

Domicó, N. (2018). Guardianas de la sabiduría: pedagogía de los cantos ancestrales del pueblo Embera Eyabida (tesis de pregrado). Medellín: Universidad de Antioquia.

Escobar, A. (2018). Otro posible es posible: caminando hacia las transiciones desde Abya yala/afro/ Latinoamérica. Desde Abajo.

Fox, M. V. (1988). Guillermo Jorge Manuel José. Ekare.

Geertz, C. (2003). La interpretación de las culturas. Gedisa.

Green, A. (2011). Significados de vida: espejo de nuestra memoria en defensa de la madre Tierra (tesis de doctorado). Medellín: Universidad de Antioquia.

Larrosa, J. (2004). Conferencia: la experiencia y sus leguajes. En La experiencia y sus leguajes (pp. 1-11). Universidad de Barcelona.

Larrosa, J. (2006). Sobre la experiencia. Aloma: Revista de Psicologia, Ciències de l'educació i de l'esport Blanquerna, 19, 87-120. 
Mateo, N. (2017). Hacer/siendo común: educación comunitaria en los chatinos de Tataltepec de Valdés, Oaxaca (tesis de maestría). Ciudad de México: Universidad Pedagógica Nacional.

Montes, G. (2001). La frontera indómita. En torno a la construcción y defensa del espacio poético. Fondo de Cultura Económica.

Platón (1925). El sofista. Traducido por Aguste Diaz. Citado en Ricoeur, P. (2000). Memoria, historia y olvido. Fondo de Cultura Económica.

Ricoeur, P. (2000). Memoria, historia y olvido. Fondo de Cultura Económica.
Rojas, P. (2014). A contraluz tejiendo. Aproximación crítica desde una perspectiva intercultural a otras formas de construir conocimiento (tesis de maestría). Medellín: Universidad de Antioquia.

Santamaría, F. A. (2010). El relato autobiográfico: una experiencia como aporte a la construcción de identidad en jóvenes estudiantes universitarios. En S. F. Alba, En diálogos con jóvenes (pp. 53-66). Universidad Distrital Francisco José de Caldas.

Torres, A. (2013). El retorno a la comunidad. El Búho.

Zemelman, H. (2002). Necesidad de conciencia. Un modo de construir conocimiento. Anthropos. 